\title{
O livro didático e sua presença em aulas de História: contribuições da etnografia
}

\section{The textbook and its presence in History classes: contributions of ethnography}

\author{
Edilson Aparecido Chaves*
}

\begin{abstract}
RESUMO
A pesquisa investiga formas de uso do livro didático nas aulas de História, destacando o ponto de vista de alunos e professores do Ensino Médio. Analisa relações estabelecidas com o conhecimento histórico a partir de livros didáticos de História incluídos no Programa Nacional do Livro Didático (PNLD). A pesquisa, de natureza etnográfica, foi realizada entre 2010 e 2014. O trabalho empírico foi realizado em uma Escola do Campo com a colaboração de três professores de História e seis turmas de ensino médio, totalizando cento e doze alunos. Como principal estratégia de pesquisa foi utilizada a observação participante. Foram realizadas entrevistas e análise documental e foram utilizados outros instrumentos na forma de questionários e de atividades realizadas para análise de livros didáticos com os alunos. Os resultados permitiram constatar diferentes relações que professores e alunos estabelecem com o conhecimento histórico a partir do uso dos livros didáticos e evidenciaram contribuições das abordagens etnográficas para o estudo dos processos escolares e, em particular, para compreender as formas de utilização dos livros didáticos nas aulas.

Palavras-chave: Didática da História. Livro didático de História. Escola do Campo. Etnografia.
\end{abstract}

\footnotetext{
ABSTRACT

This research aims to investigate different ways of using textbooks in History classes, highlighting the point of view of high school students and teachers. It also analyzes established relations with historical knowledge

* Instituto Federal do Paraná. Curitiba, Paraná, Brasil. Integrante do Núcleo de Pesquisa em Publicações Didáticas (NPPD/UFPR). E-mail: edilsonhist@gmail.com. https://orcid.org/0000-
} 0002-4909-8059. 
obtained in History textbooks included in the Brazilian National Textbook Program (Programa Nacional do Livro Didático - PNLD). This study has an ethnographic nature, and it occurred between 2010 and 2014. The empirical work was made within a Countryside School with the collaboration of three History teachers and six groups of students in high school (a total of one hundred and twelve students). The main strategy used was the participant observation. Interviews and documental analysis were made, and other tools were used, like questionnaires and activities in order to help students to analyze textbooks. The results allowed to perceive different relations that teachers and students established with historical knowledge by using textbooks, which highlighted the contributions of ethnographic approach to the study of educational processes and, more specifically, to understand the ways to use such textbooks in classes.

Keywords: History didactics. History textbook. Countryside School. Ethnography.

\section{Questões introdutórias sobre o livro didático no ensino de História ${ }^{1}$}

O livro didático se faz presente na vida da maior parte das escolas brasileiras, seja no processo de alfabetização, seja para o aprendizado das várias ciências que sustentam as disciplinas escolares. Em um universo diversificado de materiais para ensino já existentes, o livro ainda ocupa um papel central na escolarização de crianças e jovens.

Batista argumenta que "os livros didáticos parecem ser, assim, para parte significativa da população brasileira, o principal impresso em torno do qual sua escolarização e letramento são organizados e constituídos" (BATISTA, 1999, p. 53). E afirma que é preciso, desse modo, conhecer melhor esse impresso que terminou por se converter na principal referência para a formação e a inserção no mundo da escrita de um expressivo número de docentes e discentes brasileiros e, consequentemente, para a construção do fenômeno do letramento no país.

No Brasil o livro didático ocupou e ocupa um importante papel dentro da cultura escolar e, principalmente, na estruturação das aulas. Tal presença, ao longo do tempo, faz com que se compreenda a importância das palavras de Abud (1984, p. 81): “O livro didático é um dos responsáveis pelo conhecimento histórico que constitui o que poderia ser chamado de conhecimento do homem

1 Este artigo reproduz de forma aproximada partes do texto que compõe tese defendida em 2014 (CHAVES, 2015). 
comum". Visto dessa forma, o livro didático é um dos grandes responsáveis pela constituição de um conhecimento específico da História que, possivelmente, será entendido como verdadeiro e legítimo pela maior parte das pessoas comuns, já que foi transmitido pelos manuais ao longo da vida escolar das crianças e jovens.

Katia Abud (1984, p. 81) argumenta que "esse homem comum, em geral, vê a história como uma epopeia ou como um suceder de fatos pitorescos, cujos personagens principais são os vultos históricos, os heróis que movem a história. A narração dos feitos desses indivíduos constituiria, então, a História para esse homem comum".

Portanto, para a autora, as ideias contidas em alguns manuais didáticos muitas vezes são reforçadas pelos professores que, ao narrar os fatos e as ações dos grandes heróis, contribuem para a construção de uma compreensão simplificada e equivocada de História e, também, para que os manuais sejam vistos como única fonte confiável do conhecimento histórico (CHAVES, 2015).

Localizando-se essa discussão na década de 1980, afirmava a autora que "esta tendência à simplificação/distorção é mais evidente nos livros destinados ao $1^{\circ}$ grau" [...]. Também afirmava que "as tentativas de renovação são mais evidentes nos livros de História do Brasil para o $2^{\circ}$ grau, quer nos parecer, porque existe um consenso de que no $2^{\circ}$ grau ela pode ser analisada e discutida mais profundamente, dado o amadurecimento dos alunos" (ABUD, 1984, p. 82) ${ }^{2}$.

A elaboração dos Parâmetros Curriculares Nacionais (PCNs), na década de 1990, trouxe outras orientações para os livros didáticos de todo o Ensino Fundamental e Médio, na perspectiva geral de que o aluno, ao longo de sua trajetória escolar, deve ser capaz de "questionar a realidade formulando-se problemas e tratando de resolvê-los, utilizando para isso o pensamento lógico, a criatividade, a intuição, a capacidade de análise crítica, selecionando procedimentos e verificando sua adequação" (BRASIL, 1998, p. 8).

Nos PCNs, uma das discussões sobre o ensino de História apontava que "a História para os jovens do Ensino Médio possui condições de ampliar conceitos introduzidos nas séries anteriores do Ensino Fundamental, contribuindo substantivamente para a construção dos laços de identidade e consolidação da formação da cidadania" (BRASIL, 1999, p. 22).

Pode-se dizer que essas finalidades e objetivos foram transferidos para a avaliação dos livros didáticos, determinando critérios gerais e específicos que acabaram por consolidar algumas formas de renovação na seleção de conteúdos para o ensino da História, colocando à disposição dos professores, seja das séries iniciais ou das séries finais, um conjunto de obras que, pelo menos

2 Primeiro Grau e Segundo Grau são as denominações que correspondem ao Ensino Fundamental de 8 anos e ao Ensino Médio, pela Lei n ${ }^{\circ}$ 5.692/71. 
em tese, incorporaram as renovações historiográficas e, portanto, apresentam inovações no que diz respeito aos conteúdos a serem ensinados em História (CHAVES, 2006, p. 46-47).

A preocupação com os livros didáticos, contudo, não é uma questão recente. As primeiras investigações públicas sobre o livro didático de História podem ser encontradas na obra de Guy de Hollanda, professor da Faculdade Nacional de Filosofia do Rio de Janeiro. Seu trabalho, intitulado Um quarto de século de programas e compêndios de história para o ensino secundário brasileiro (1931-1956), foi realizado a pedido do Instituto Nacional de Pesquisas Educacionais - INEP.

Um segundo balanço, que resultou em documento intitulado $O$ estado $d a$ arte do Livro Didático no Brasil, foi produzido por Barbara Freitag e outros autores. Publicada em 1987, também por solicitação do INEP, a pesquisa faz uma análise estrutural da presença do livro didático no sistema educacional brasileiro. Não se trata, no entanto, de uma obra específica sobre os livros didáticos de História.

Segundo Freitag, o principal objetivo do projeto era resgatar documentos como teses, livros, artigos e legislação sobre livro didático no Brasil, e o catálogo divide a obra por disciplina ou área do conhecimento. Relembra-se que, naquele momento, a História havia perdido seu lugar específico no currículo e, portanto, os autores examinam os livros de Estudos Sociais.

$\mathrm{Na}$ esteira do trabalho de Freitag, Motta e Costa, em 1989 foi publicado um catálogo analítico, também financiado pelo INEP. Intitulada Que sabemos sobre Livro Didático: catálogo analítico, a obra foi organizada a partir de trabalho envolvendo pesquisadores da Biblioteca Central da Faculdade de Educação e do Instituto de Estudos da Linguagem da UNICAMP (Universidade Estadual de Campinas).

Desde então, algumas transformações ocorreram e devem ser apontadas. Primeiramente, a História recuperou sua especificidade no currículo do Ensino Fundamental e Médio e, assim, também os livros didáticos voltaram à sua especificidade. Com isso, novas perspectivas para o ensino de História foram incorporadas também pelos autores e editoras, muito especialmente pressionados pela forma como o Programa Nacional do Livro Didático (PNLD) incorporou parte dos debates acadêmicos aos critérios de avaliação dos livros.

A presença dos livros didáticos na vida escolar brasileira nas últimas décadas, decorrente das ações do PNLD, motivou um significativo crescimento no número de pesquisas sobre o tema. Contribuições têm sido dadas por diferentes grupos de pesquisa que investigam temas relacionados ao livro didático de História, entre os quais o Núcleo de Pesquisa em Publicações Didáticas da Universidade Federal do Paraná (NPPD/UFPR). 
$\mathrm{Na}$ esteira de trabalhos avaliativos da produção acadêmica como os já referidos, cita-se a tese de doutoramento de Anne Cacielle Ferreira da Silva, intitulada Estado do conhecimento sobre o livro didático de história em dissertações e teses produzidas em programas de pós-graduação no Brasil (1990-2015). Tomando como material empírico os resumos de dissertações e teses produzidas entre os anos de 1990 e 2015 que estão disponibilizadas virtualmente em base de dados, a autora localiza os centros produtores de conhecimento em torno do tema livro didático de História e sobre seu uso por alunos e professores, e analisa essa produção localizando 229 pesquisas que incluem a expressão "livro didático de história” em seu título, palavras-chave ou resumo (SILVA, 2018).

A pesquisa contribuiu para identificar as pesquisas realizadas em Programas de Pós-Graduação no país, mas, para além disso, evidenciou focos e temas privilegiados pelos pesquisadores, bem como as abordagens metodológicas utilizadas e o nível de formação do pesquisador, entre outros aspectos, o que permite compreender as tendências, as recorrências e os temas lacunares. Ressalta-se que os estudos históricos são os mais frequentes e que os estudos sobre a presença dos livros nas aulas ainda são pouco realizados.

Outra contribuição a destacar é a de Moraes (2018), que realizou investigação sobre o papel do guia do livro didático de história/PNLD no processo de escolha dos livros pelos professores dos anos finais do ensino fundamental - tema ainda pouco focalizado pelas pesquisas acadêmicas. O autor descreve as mudanças ocorridas nos guias no período de 2002 a 2017, especialmente quanto aos aspectos do conhecimento especifico da História; analisa também o acesso e a utilização, pelos professores, do Guia do Livro Didático de História em 2017, tanto na forma impressa quanto na digital. Moraes problematiza os significados desse material que se "materializa apenas esporadicamente na vida escolar, no curto período de tempo em que os livros devem ser escolhidos" (MORAES, 2018).

As considerações aqui apresentadas podem ser tomadas como elementos justificadores da necessidade de ampliar os estudos sobre os livros didáticos nas escolas e nas aulas. Entende-se que é preciso compreender como professores e alunos se relacionam com esse objeto da cultura escolar, objetivo que dirigiu a pesquisa relatada, em parte, neste artigo. Foram selecionados alguns dos resultados obtidos, com a intenção de explicitar as condições em que se deu a aproximação etnográfica com a escola e com a sala de aula, bem como as análises que se tornaram possíveis a partir desse processo de investigação. 


\section{Dinâmicas de trabalho na escola e as relações entre a escola e a comunidade local}

A pesquisa para a tese intitulada $A$ presença do livro didático de história em aulas do ensino médio: estudo etnográfico em uma escola do campo (CHAVES, 2015) acompanhou o trabalho em uma escola pública durante um ano letivo e a observação participante foi a principal estratégia utilizada na produção dos dados. Foi possível acompanhar 140 aulas de História ao longo do ano letivo, acompanhando três turmas $\left(1^{\circ}, 2^{\circ}\right.$ e $3^{\circ}$ anos do Ensino Médio) no primeiro semestre e três turmas $\left(1^{\circ}, 2^{\circ}\right.$ e $3^{\circ}$ anos do Ensino Médio) no segundo semestre do mesmo ano.

A permanência na Escola Mundial $^{3}$ iniciava às sete horas e trinta minutos e findava às onze horas e trinta minutos, todas as quartas-feiras. A observação foi complementada com a realização de entrevistas e conversas informais, questionários e por meio de outros instrumentos específicos para avaliação dos livros didáticos, além de análise documental. Aulas de outras disciplinas também foram observadas, além de atividades didáticas com diferentes finalidades, reuniões pedagógicas, uma reunião de pais, um conselho de classe e outros eventos que geralmente se davam nos intervalos das aulas (CHAVES, 2015).

Na perspectiva metodológica assumida, com base em Rockwell e Ezpeleta (2007) e Garcia (2001), valoriza-se a inserção do pesquisador no cotidiano escolar para observar, conversar com os participantes, entrar em contato com documentos e, assim, compreender as dinâmicas que constituem a vida escolar, de forma mais ampla, para gradativamente (re)definir as questões de pesquisa e finalmente focalizar o estudo em determinados processos que se relacionam com o tema selecionado para a pesquisa. Assim, as primeiras atividades de observação permitiram fazer a aproximação inicial com a comunidade escolar e alguns elementos foram selecionados para apresentação neste artigo.

A chegada de todos os alunos à escola se dava basicamente ao mesmo tempo, dado que a maioria vinha no ônibus escolar. Tal situação permite à escola uma maior organização do início das atividades, pois não há atraso por parte do aluno. Os ônibus escolares chegam por volta das $7 \mathrm{~h} 20 \mathrm{~min}$. As aulas iniciam às $7 \mathrm{~h} 30$ e terminam às $11 \mathrm{~h} 30$. Para tentar minimizar um problema existente, qual seja, o abandono da escola por muitos alunos, a Direção, juntamente com professores, optou pela organização curricular por blocos, oferecida pelo Estado

3 Todos os nomes dos participantes são fictícios, no sentido de preservar a identidade dos sujeitos colaboradores e da escola onde ocorreu a pesquisa. 
como uma possibilidade diferenciada de disposição das disciplinas: o aluno matricula-se na série que deseja cursar e tem no primeiro semestre um conjunto de disciplinas que não se repetirá no segundo semestre. Assim, a carga horária de cada disciplina fica concentrada em um dos dois semestres e não se distribui ao longo de todo o ano.

Durante o período de aulas, a escola é muito tranquila, pouco se via alunos pelos corredores ou fora da sala de aula. A tranquilidade era quebrada no momento do intervalo para lanche, em que todas as turmas do ensino fundamental e médio se reuniam em um espaço destinado à alimentação.

Os alunos mantinham boa relação com os professores e na maior parte do tempo as relações eram respeitosas. Os professores mais antigos da escola pareciam contornar melhor as situações de tensão e raramente foi possível observar atitudes de retirada dos alunos das aulas, prática ainda existente em algumas escolas, apesar das críticas a essas formas de atuar sobre questões de indisciplina.

Em geral, as atividades escolares ocorriam dentro das salas de aula. Algumas aulas foram realizadas no campo de areia para práticas de esportes. Relata-se uma das situações em que as atividades foram realizadas nesse espaço. $\mathrm{O}$ pesquisador se encontrava em intervalo entre as aulas de História e caminhava no pátio aberto. Havia no campo de areia um grupo de alunos com o professor de Sociologia, disciplina que pertencia ao bloco $2^{4}$ e, portanto, não eram os mesmos alunos das aulas de História.

O professor está no meio e um círculo de alunos ao redor. Todos estão com um texto nas mãos, uma fotocópia. Procurei me aproximar de forma a não atrapalhar o andamento da aula, e percebo que estão discutindo Maquiavel. O professor fala do papel político na vida dos alunos e faz uma comparação com o local em que vivem - que ele chama de Comunidade da Escola Mundial. Alunos leem em voz alta o texto e o professor faz indagações. $\mathrm{O}$ professor pergunta se alguém não entendeu nada. Uma aluna fala que o texto é difícil, ele faz outra comparação e cita o desenho dos Simpsons para buscar aproximação entre as discussões e os alunos. Volta a explicar o contexto de Maquiavel - fala do livro "O Príncipe" e do século XVI, quando o texto foi criado. Uma aluna começa a fazer uma discussão com o professor sobre o texto, faz indagações, o professor a

4 Para o Ensino Médio, a escola adotou o sistema de Blocos, alternativa criada no Estado do Paraná para a organização administrativa e pedagógica da grade horária. A Escola Mundial fez essa opção, passando a adotar uma Matriz Curricular Única, com implantação simultânea em todas as turmas. Por esse modelo, três turmas tinham a disciplina de História no primeiro semestre e não teriam no segundo semestre, quando as demais é que a teriam. Portanto, no primeiro semestre, as observações para o acompanhamento das aulas foram feitas nas turmas do Bloco 1 . 
elogia. Os alunos se mostram interessados, entre uma explicação e outra fazem leitura em voz alta. Continuam em círculo. O professor faz outra relação com o mundo dos jovens e diz: "se vocês pudessem enviar um twiter para Maquiavel com 140 caracteres o que escreveriam? Lembrem-se, pessoal, criticar não é falar mal".

O professor dá cinco minutos para que os alunos escrevam, em grupo ou individualmente. No momento da leitura uma aluna diz que não quer ler, pois pode estar errado. Ele fala: "não é questão de estar errado, são suas palavras". Uma aluna critica o modo como Maquiavel trata a religião e diz que discorda da posição do autor sobre o tema. Outros alunos afirmam a mesma coisa. Esses alunos são descendentes de poloneses, com forte traço católico; a escola se situa atrás da igreja, que é uma capela católica, algumas salas de aula são alugadas da igreja, funcionam nos finais de semana como sala de catequese e possuem imagens de santos na parede. O professor faz uma interferência dizendo que é uma aula de sociologia e não de religião e que é preciso compreender o mundo em que Maquiavel viveu. Outros alunos vão um pouco à frente dos outros e realizam suas leituras; ouve cada um e comenta fazendo indagações (Notas de campo. Maio de 2012).

A observação desta situação contribuiu para reafirmar a necessidade de considerar as questões da cultura local como elementos que afetam de diferentes formas a produção das aulas e o conhecimento que está em processo de ensino e aprendizagem. Em um período posterior da pesquisa de campo, foi possível analisar aulas de História em que a professora propôs uma atividade para relacionar o conteúdo com a experiência dos alunos.

Outro ponto a destacar se refere à organização das relações estabelecidas entre direção, alunos, pedagogos, professores e pais. Quando ocorria qualquer situação de desconforto ou tensão com os professores, os jovens procuravam resolver o problema diretamente com a direção da escola, evidenciando-se então o trabalho dos pedagogos, que usualmente também cumprem essa função de mediação.

Em consequência dessa prática, o pesquisador pôde observar algumas situações em que havia na sala da diretora um número significativo de alunos fazendo suas reivindicações e que, quando não havia consenso entre direção e estudantes, os pais procuravam a escola nos dias seguintes para resolver os problemas.

Por outro lado, os professores tinham maior proximidade com o pedagogo, que no momento do lanche estava sempre presente na sala dos professores e ouvia deles os mais variados pedidos na tentativa de resolver problemas relacionados à aprendizagem dos alunos, ou outros casos mais extremos, como mudança de sala em função do comportamento inadequado nas aulas. As observações rea- 
lizadas quanto às dinâmicas gerais de funcionamento da escola evidenciaram recorrências nas formas de relação entre os diferentes participantes daquela comunidade e assim se pode dizer que há na Escola Mundial um bom atendimento aos alunos e suas necessidades.

As atividades estão concentradas nos horários de aula e poucas são oferecidas em horário complementar. Observou-se em apenas um momento a realização de uma atividade extraclasse, com um campeonato de tênis de mesa, em que cerca de oito alunos de diferentes níveis de ensino participaram. O campeonato foi organizado pela coordenação pedagógica e premiou ao final o vencedor com um troféu.

Os alunos do Ensino Médio se encontravam no momento do intervalo para jogar cartas, atividade proibida pela Direção. Para escaparem do controle das inspetoras, usavam cartas do baralho de um jogo conhecido como Uno que, por ser um jogo educativo, era permitido. No entanto, as cartas do Uno eram marcadas com símbolos desenhados pelos próprios alunos, transformando-as em cartas do jogo de baralho conhecido como truco burlando o sistema de controle e realizando, assim, a atividade que desejavam sem serem notados.

A merenda era servida todos os dias com variedade de cardápio. Os alunos aguardavam em fila a entrega dos pratos pelas cozinheiras e se sentavam a uma das mesas para se alimentar. A mesma merenda era também servida para os professores. Alguns professores permaneciam na escola no turno da tarde e dividiam as despesas para comprar outros tipos de produtos para que lhes fossem servidos durante o almoço.

A participação da comunidade é uma constante na escola. Observaram-se sinais de que existe uma cobrança por parte dos pais quanto à organização da escola e ao atendimento aos alunos. Por muitas vezes, o pesquisador percebeu na chegada dos ônibus no período da manhã que alguns pais vinham para conversar com professores ou com a Direção.

Em conversas informais com professores que também moram na região, pôde-se saber que as famílias que estão há mais tempo na região, muitas delas descendentes dos primeiros povoadores, eram mais exigentes, sobretudo quando se tratava do comportamento dos filhos. Para esses professores, os alunos que nasceram em áreas rurais são diferentes, bem comportados e mais compromissados do que os provenientes das áreas urbanas, das famílias que vieram viver na localidade mais recentemente.

Estas características marcam a vida escolar e, portanto, também a forma como acontece o trabalho nas aulas. Na seção seguinte, são apresentados alguns dos resultados que permitiram discutir, para além das dinâmicas sociais naquele espaço, as relações com o conhecimento histórico nesta situação específica de escolarização, em uma escola do campo. 


\section{Formas de uso do livro didático de História}

O tema central que dirigiu a pesquisa articula-se em torno das relações que jovens alunos e professores de Escolas do Campo estabelecem com o livro didático em aulas de História. A investigação de caráter etnográfico permitiu compreender alguns elementos dessa relação, propondo-se também conhecer os critérios que utilizam para avaliar a qualidade de tais livros (CHAVES; GARCIA, 2014).

A observação participante nas aulas de História da Escola Mundial foi fundamental para a construção da pesquisa. Três professores colaboradores dessa escola ensinaram História para os jovens do Ensino Médio, durante o ano letivo de 2012, em consequência de processos administrativos de substituição e novas contratações. Apesar das dificuldades decorrentes desses processos, os professores abriram o espaço de suas salas de aula para que a pesquisa fosse realizada, contribuindo para que as questões pudessem sem compreendidas.

Por outro lado, acompanhar o trabalho de profissionais com diferentes características possibilitou compreender como as formas pelas quais inserem o livro em suas aulas expressam determinados tipos de relação dos professores com o conhecimento histórico. Também foi possível verificar como essas formas de uso afetam as relações dos alunos com o conhecimento histórico, em alguns aspectos específicos.

Foram selecionados alguns desses elementos, a partir dos registros feitos em determinadas aulas. Contudo, deve-se destacar que não se trata de associar cada situação a um modelo de professor ou de aula; algumas formas de uso apareceram, embora com diferentes intensidades e matizes, nas aulas dos três professores (CHAVES, 2015).

\section{O livro, a cópia e as "curiosidades históricas"}

De forma geral, pode-se dizer que o professor Marcio e a professora Clarice tinham maneiras semelhantes de trabalhar - utilizavam-se de outras fontes e criavam materiais diferenciados para ensino, mesclando elementos da história local à história estudada no livro didático, que era utilizado como um recurso em suas aulas.

A professora Joana organizava suas aulas de outras formas. Manifestando-se inicialmente em desacordo com o livro que estava em uso na escola, relatou 
em conversa informal que participou de sua escolha no ano anterior, mas destacou que o livro escolhido não foi aquele que o PNLD enviou para a escola. Essa é uma questão referida com frequência nas pesquisas sobre o livro didático; por motivos nem sempre explícitos, as escolas recebem o livro que foi pedido como segunda opção e, algumas vezes, recebem livros que não solicitaram. Portanto, a professora manifestou sua insatisfação pelo fato de ser obrigada a utilizar um livro que não considera adequado ao seu trabalho. Em seu primeiro dia de aula na Escola Mundial com a turma do primeiro ano, substituindo o professor Marcio, que havia sido chamado para assumir aulas em outra escola, Joana entrou na sala e de imediato começou a escrever no quadro um resumo sobre a Grécia Antiga. Em seguida, ao explicar o resumo, dirigiu-se aos alunos e disse: "Gente, vou usar o livro de História para tarefa e retomar o conteúdo da prova" (Registros de campo, 11/04/2012).

O decorrer das aulas, no entanto, trouxe outras formas de uso do livro além daquele que a professora Joana havia anunciado. Além de passar tarefas e pedir que estudassem para a prova, ela o utilizou como fonte de informação para suas explicações, bem como para leitura pelos alunos e para apresentar elementos que deveriam ser anotados pelos alunos nos cadernos, muitas vezes na forma de ditado. As mesmas formas de trabalho foram observadas nas aulas das outras turmas, como se pode acompanhar no registro de uma aula do segundo ano, reproduzido a seguir:

9:08h

Professora Joana pega caderno da aluna e diz que vai retomar a aula do dia anterior. Professora: "Voltando para a História do Brasil"... " A cana-de-açúcar"... Alunos a interrompem.

Professora: "Informação importante: o açúcar era produzido no engenho". Aluno: "E a pinga também, professora?" (Todos sorriem)

Aluna Tayana diz baixinho para as amigas: "Se fosse o professor Marcio falaria de todo o processo da produção do açúcar".

Aluna: "E o pau-brasil?"

Professora: "Servia para produzir tinta".

$9: 15 \mathrm{~h}$

A professora, com o livro nas mãos, escreve no quadro. Pego meu exemplar do livro e verifico que o tema está na página 103.

Aluna (sentada à minha frente pega o livro, olha para a página e diz para a colega): "Nossa... olha como era um Engenho..."

Outro aluno escuta, pega o livro e afirma: "Isso é feudal..."

Aluna Tayana diz (aparentemente em tom de cobrança): "Explica aí, professora..." 
A Professora pede para todos abrirem na página 103. Lê uma nota explicativa sobre o Engenho. Fala do processo de plantação da cana-de-açúcar. Não consegue se lembrar de algumas fases e pergunta se eu sei. Contribuo com a informação solicitada e pergunto aos alunos quantos já viram um pé de cana-de-açúcar. Nenhum aluno diz conhecer.

$[\ldots]$

No fundo da sala, alguns alunos se mantêm distantes da discussão e conversam sobre celular.

$9: 33 h$

A professora diz: "Anota aí no caderno". (Começa a ditar) "Os holandeses no Nordeste...".

Os alunos param de conversar e começam a escrever. Abro meu livro e verifico que o texto ditado está na página 104.

9:40h - Termina o ditado. Os alunos guardam o material...

9:45h - A aula é finalizada. (Notas de campo, 18/04/2012).

As observações de aula permitem afirmar que os alunos pareciam ter na maior parte das vezes a expectativa de uma continuidade das explicações dadas pela professora Joana. O registro de campo mostra como os alunos procuram ir acrescentando informações, contribuindo com a explicação apresentada, bem como fazem referência a conteúdos (textos ou imagens) que estão no livro e que não foram destacados pela professora.

A representação do engenho, por exemplo, estava apresentada no livro e chamou a atenção da aluna, embora não tivesse maior consequência para o andamento da aula. Trata-se da representação de um engenho colonial (na página 103 do livro utilizado $)^{5}$ que mostra o processo da produção da cana-de-açúcar no Brasil, inclusive incluindo um elemento extremamente importante, os sujeitos - índios e escravizados, que raramente foram incluídos nas explicações da professora.

Outro ponto a destacar, nesse registro de campo, é a observação da aluna em relação à diferença de procedimentos entre a professora atual e o anterior, especialmente neste caso com relação às explicações sobre "o processo todo". Efetivamente, o professor usava o livro como uma referência e a partir dele costumava dar explicações bastante detalhadas quanto aos processos em estudo.

Esta questão define o que se deseja colocar em destaque nesta seção quanto à forma de relação da professora com o conhecimento histórico que se

5 Trata-se do livro Coleção Novo Olhar: História, de Marco Pellegrini, Adriana Machado Dias e Keila Grinberg, publicado pela editora FTD em 2010. 
manifesta e se materializa também na forma como ela utiliza o livro e que define, em consequência, um tipo de relação dos alunos com esse conhecimento. A estruturação das aulas de História da professora Joana estava apoiada na ideia de apresentar aos alunos o tema a partir de uma "curiosidade histórica". O que isso significava concretamente na organização de aulas de História? A aula pauta-se na apresentação de um tema, em geral canônico, que chama a atenção para um "fato importante" da História e que deve ser memorizado pelos alunos.

Ao anunciar nas aulas que um tema histórico é uma curiosidade, a professora Joana revela uma forma de relação com o conhecimento histórico que exclui a problematização e a necessidade de interpretação de fontes para construir explicações históricas. Era comum nas aulas a professora dizer: "Curiosidade... anotem ai....". Seguia-se, de forma geral, a indicação de um fato histórico que ela entendia ser necessário destacar para que os alunos memorizassem. De forma coerente com sua concepção, o uso do livro correspondia ao aproveitamento de alguma informação apresentada na obra, reproduzindo-a oralmente ou mesmo no quadro, para os alunos copiarem.

Do ponto de vista das atividades, a mesma concepção definia a forma de trabalho e de uso do livro didático. O capítulo do livro que trata da agricultura inclui documentos que podem ser usados para os alunos discutirem e criarem possibilidades de interpretação sobre o tema, como sugerem os objetivos específicos do manual do professor (PELLEGRINI; DIAS; GRINBERG, 2010, p. 53), apontando que aquele capítulo deveria possibilitar ao estudante "compreender o funcionamento da sociedade colonial, no meio rural e no meio urbano".

Esta seria uma das temáticas que possibilitaria estabelecer relações com a cultura dos alunos, por exemplo, para problematizar o presente e ir ao passado, que está presente nos documentos apresentados no livro, em busca de explicações históricas. No entanto, a organização didática nas aulas não assumiu essa perspectiva, deixando de levar em consideração que a seleção do conteúdo a partir das carências dos alunos poderia criar propostas de entendimento do presente e do passado.

A professora Joana solicitou aos alunos o trabalho com questões relacionadas aos meios rural e urbano. Os alunos realizaram as atividades, no entanto, não houve um momento de socialização dos resultados para confrontar os olhares diversos sobre o longo período que foi objeto do resumo dos jovens ${ }^{6}$. Assim, o valor da atividade restringiu-se a sua avaliação pela professora.

6 A professora solicitou aos alunos um resumo que discutisse o paralelo entre a situação dos trabalhadores durante a República Velha (1889-1930) e o Brasil atual, levantando informações e fazendo comparação com a seguinte questão: Qual a situação dos trabalhadores do campo e da cidade hoje? 
Em outra situação semelhante de correção da tarefa solicitada, uma das alunas de terceiro ano disse: "Hoje em dia os professores não dão nota pelo que a gente pensa e sim pelo que está escrito no caderno" (Notas de campo, 09/05/2012). Em decorrência do tipo de relação estabelecida com o conhecimento histórico, a ação docente privilegiava a realização de atividades mecânicas, individuais e com vistas à reprodução de ideias. E o livro, nesse caso, é incorporado para cumprir funções que se relacionam ao registro de ideias prontas muito mais do que à construção de conhecimentos pelos jovens, como bem observou a aluna Brenda.

O conhecimento escolar produzido nas aulas, neste caso, pode ser entendido na perspectiva do que Edwards (2003) denominou "forma de conhecimento tópico", que leva os alunos a acreditarem que o conhecimento é algo pronto e acabado e que, portanto, basta reproduzi-lo para que obtenha ao final do ano escolar a aprovação para a série seguinte.

Destaca-se que a professora não era formada na área específica de História; de forma mais acentuada que os dois outros professores, ela revelava dificuldades com os conteúdos históricos do livro em uso. Segundo Fonseca (2003, p. 56), "o livro didático é uma das fontes de conhecimento histórico e, como toda e qualquer fonte, possui uma historicidade e chama a si inúmeros questionamentos". Assim, embora sendo suporte de conhecimentos, o livro necessita ser interpelado por professores e alunos para que os conteúdos sejam ressignificados - dificuldade que se acentuava em grande parte no caso de Joana, pela ausência de uma formação específica para ensinar História, apesar dos seus esforços.

Ao fazer tal afirmação, entende-se que, na formação do professor de História, a aprendizagem acerca do trabalho com diferentes materiais para ensino, entre eles o livro didático, deve ser objeto de aprofundamento, pois, como aponta Timbó (2009, p. 4-5):

[...] trabalhar com o livro didático requer uma série de conhecimentos, historiográficos e pedagógicos, que otimizem sua utilização, percebendo-o como um documento que comporta vários outros documentos na sua estrutura, ou seja, além do texto principal de cada capítulo, um volume didático traz, em geral, uma série de fontes textuais e iconográficas, como também diferentes linguagens visuais.

A compreensão dessa ideia, entre outras, contribuiria para que a professora Joana certamente uma profissional compromissada com o ensino e nitidamente 
dedicada a apresentar o conteúdo aos alunos - fizesse um uso mais adequado do livro como um recurso de ensino. Os documentos poderiam ser analisados e utilizados para os alunos construírem narrativas, inclusive a partir dos seus interesses, como observado no caso da imagem do engenho que, de forma autônoma, os alunos trouxeram para o centro da aula, contribuindo com sua produção.

\section{O livro, os documentos e a construção do conhecimento histórico}

Os professores Marcio e Clarice, como afirmado, tinham maneiras semelhantes de trabalhar e explorar o livro didático e com frequência explicavam e analisavam, juntamente com os alunos, tabelas, vídeos e documentos, situando esses elementos historicamente.

É provável que tal situação se deva, em grande parte, ao fato de a formação de ambos ter sido na área específica de História. No instrumento de pesquisa utilizado com os professores de História da Escola Mundial, o professor Marcio assim manifestou sua opinião sobre o livro didático de História em uso na escola, tomando como referência o seu trabalho nas aulas e a aprendizagem dos alunos:

Vejo o livro didático como mais um instrumento de apoio ao estudo da história de maneira sistemática, entretanto, o conteúdo a ser trabalhado em sala deve estar no professor e este precisa direcionar a aula conforme a necessidade de cada classe. Por outro lado, o livro didático é um instrumento de "visualização" da história para os alunos, assim, seus textos remetem aos acontecimentos em si. Desta maneira, a variação entre os "conteúdos" dos livros didáticos é de menor importância. Assim sendo, cada professor deve "extrair" o melhor de cada livro e ignorar/demonstrar/adaptar o pior de cada um deles. Portanto, sou um tanto indiferente quanto ao 'modelo' de livro adotado, uma vez que todos representam certa visão de história que por vezes não é aquela que o aluno vê como significativa. Retornando ao que já foi dito, cabe ao professor adaptar o livro/conteúdo à classe e não o contrário (Marcio, registro feito em instrumento escrito, 2012).

A mesma questão foi respondida pela professora Clarice, que destacou elementos de avaliação do livro, apontando pontos positivos, falhas e lacunas que ela percebe: 
A coleção "Novo Olhar" de Pellegrini, Dias e Grinberg apresenta uma boa diagramação, com linguagem acessível, cronologias, mapas, figuras, exercícios de fixação e interpretação interessantes. No entanto, os autores usaram as fontes primárias e secundárias como ilustrativas do conteúdo. As fontes secundárias foram utilizadas principalmente nos exercícios "expandindo o conteúdo", em que o aluno interpretaria e mediaria o conteúdo de História com o presente. Na minha opinião, para o trabalho em sala e para o aprendizado dos alunos, um livro que incluísse diversas fontes históricas para interpretação, outras referências em relação ao presente, seria mais útil.

Ambos expressam opiniões sobre o livro didático em uso, mas com elementos distintos. Enquanto Marcio referiu-se de forma genérica a finalidades do livro e ao tipo de relação que ele estabelece com este "instrumento de apoio", Clarice foi precisa ao apontar elementos específicos do livro de História, como a presença de documentos, e fez ressalvas quanto ao modo como o livro apresentou e tratou os documentos - como ilustração e não como fontes.

Ao encaminhar suas aulas, ambos utilizavam o livro, mas reelaboravam os temas e conteúdos e enriqueciam as aulas com outros elementos, dando possibilidade para o aluno explorar os múltiplos sujeitos participantes dos processos em estudo, assim como as fontes apresentadas no livro didático.

Para a professora Clarice, cuja principal característica era centrar o aprendizado no aluno, um bom livro didático deve apresentar de forma instigante as experiências do passado, estimulando a interpretação do aluno sobre o passado, mas também estabelecer relações com o presente, assim como oferecer condições para o aluno analisar diferentes interpretações históricas.

O ensino de História construído nas aulas da professora Clarice era sustentado em grande parte no uso do livro didático. Ao iniciar uma aula, sempre dava prioridade ao que os alunos conheciam sobre o tema, passando em seguida a explorar o que o livro trazia. A leitura era uma prática constante. Com o decorrer das aulas e uma melhor apropriação do livro, a professora começou a trabalhar com outras fontes, com vistas a preencher algumas lacunas referentes às carências temáticas em História. $\mathrm{O}$ registro a seguir evidencia algumas formas de trabalho da professora:

\section{7 h37}

Professora Clarice diz: "Gente, hoje vou aplicar para vocês... a gente vai trabalhar com fontes e eu vou aplicar algumas perguntas".

(Alunos vão se organizando para o trabalho) 
Professora entrega três páginas e diz em voz alta: "É para fazer no caderno..." (Pede silêncio)... "Então vamos lá... Alguns trechinhos que escolhi sobre os gregos... A melhor forma de conhecê-los é ver o que deixaram".

$7 \mathrm{~h} 40$

A professora lê os textos com perguntas. Alguns alunos acompanham, Wellington chama a professora e pergunta o que são os artigos da Constituição Brasileira de 1988.

A professora fala que são as leis que regem o país e que a Constituição de 1988 foi construída em momento importante da História do Brasil.

Elisson: "Nunca vi isso..."

A professora diz que é muito importante conhecer as leis, pois essa é uma das prerrogativas de um bom cidadão. [...]

Professora: "Gente, é para terminar nessa aula..."

Aproveita e passa de carteira em carteira verificando a atividade anterior.

[...]

7h52

Há um silêncio na sala.

Professora (lendo os fragmentos dos documentos): “Quem era cidadão?

Nós vimos na aula passada".

$[\ldots]$

7h59

Ederson chama a amiga para ajudá-lo a fazer a atividade.

Azim e Lucas conversam sobre o texto.

Azim: "Nossa, não dá para fazer nada de errado..." (se referindo aos artigos da Constituição)

Lucas: "Cara, aqui no Brasil tem um livro que chama Constituição, tem várias leis, nossos direitos e deveres..."

A professora vai para a carteira dos dois e faz uma discussão sobre as questões. Os alunos falam baixo e resolvem os exercícios.

$\mathrm{Na}$ minha frente, Elisson e o amigo discutem que as perguntas são semelhantes...

Eu olho as questões e aponto que as primeiras questões estão relacionadas à escravidão e as outras são relacionadas ao conceito de democracia.

8h12

Professora: "Vamos terminar na próxima aula".

Hanna não realizou as atividades, estava discutindo com as amigas alguns problemas ocorridos na comunidade (me pareceu ser algo como alguma briga entre as meninas que envolveu as famílias).

Alan: "Hanna deixa de conversar e vem me ajudar aqui".

(Notas de campo, 17/10/2012, Turma $2^{\circ}$ ano). 
Neste caso, pode-se observar que a maioria dos alunos foi envolvida no trabalho. A professora teve um papel importante na mediação entre o conteúdo do livro e os alunos, pois, na medida em que fazia a leitura dos documentos, tirava dúvidas fundamentais sobre eles sem necessariamente dar as respostas das questões propostas.

Pode-se supor que a professora Clarice, mesmo com pouco tempo de trabalho junto aos alunos, esteja construindo estratégias interessantes para ensinar História aos alunos da Escola do Campo. As dúvidas vão sendo esclarecidas no decorrer da leitura, o que possibilita ao estudante fazer anotações extras em seu caderno e às vezes no próprio livro; no momento da realização da atividade, as dúvidas são menores.

A professora Clarice justifica tal trabalho nas respostas dadas no instrumento de pesquisa que foi aplicado aos professores de História. Ela acredita que bons resultados com essa forma de trabalho podem aparecer, sobretudo porque esses alunos em geral, em casa, não têm tempo para o estudo, "já que muitos trabalham com seus pais no campo e justificam não fazer atividades em casa por falta de tempo" (Registros de campo, 2012).

Quando perguntada sobre facilidades específicas para desenvolver os conteúdos de História em uma escola do Campo, a professora aponta que: "Para o trabalho dos conteúdos de História percebe-se que, quando acompanhados dos conhecimentos prévios dos alunos e suas experiências, eles se tornam mais ricos".

\section{A relação dos conteúdos com a realidade dos jovens alunos}

Uma das questões que orientou a realização da pesquisa diz respeito às possibilidades de relação entre os assuntos apresentados pelo livro didático e a experiência social dos jovens alunos. Em particular, pretendia-se compreender essa relação em função da defesa de que há especificidades na Escola do Campo que devem ser levadas em conta no ensino. O desenvolvimento das propostas de Educação do/no Campo, ao longo das últimas décadas, consolidou essa posição de atendimento aos sujeitos que vivem em áreas rurais.

Quando perguntados se os documentos e temas apresentados nos livros analisados tinham alguma relação com a vida e a história deles, ou com alguma situação que poderia estar presente em seu futuro, os jovens apresentaram respostas com diferentes formulações. 
Algumas imagens sim [têm relação], mas algumas não. Um exemplo são os computadores que têm a ver com minha vida, já as imagens dos trabalhadores não, nem com meu futuro e acho que nem o dos jovens (Day, 14 anos).

Para os alunos, temas como Idade Média ou Egito Antigo pouco têm relação com suas vidas e de forma geral foi possível evidenciar que para eles não há conexão entre os temas do passado e sua vida presente. Por outro lado, há um entendimento por parte de outros alunos de que as histórias presentes no livro didático que eles analisaram possuem algumas relações com suas vidas, como se observa neste fragmento: "Sim, [há relação] porque moro em um lugar colonizado por poloneses que vieram após a Primeira Guerra Mundial". No entanto, o aluno entende que "com minha história não [tem relação], só com meus avós" (Edenilson, 16 anos).

Muitos alunos acreditam que o que aconteceu no passado não afeta sua vida no presente e muito menos a sua vida futura. Percebe-se que Edenilson não vê ligação entre sua História e a de seus antepassados, reduzindo assim as possibilidades de compreender relações de causalidade entre fatos históricos (a imigração decorrente da Guerra), a vida de sua família (que veio para o Brasil em determinado tempo e em determinadas condições, se instalou na região da escola, produziu sua existência ali) e a sua própria existência (como jovem filho das famílias que vieram e que hoje vive e trabalha no campo e estuda nesta escola).

Essa questão alerta para a necessidade de criar condições, nas obras didáticas e nas aulas de História, para que os alunos realizem conexões entre o momento histórico vivido e outros tempos que ajudaram a construir o presente e que, portanto, ajudam a explicá-lo.

De forma semelhante, Daniel não consegue estabelecer relação entre o passado e o presente mesmo já tendo estudado, no Ensino Fundamental, o conteúdo. "Não, porque foi uma guerra que aconteceu há muito tempo e não afeta em nada os jovens de hoje". Daniel se refere à Primeira Guerra Mundial. É importante esclarecer que esse conteúdo é abordado desde o Ensino Fundamental e este é um tema geralmente muito explorado pelos professores, por chamar a atenção dos alunos.

No discurso educacional, circula a partir de diferentes autores e perspectivas a ideia de que o trabalho a partir da realidade dos alunos promove, entre outras coisas, o desenvolvimento da capacidade de análise crítica. Na tentativa de compreender a visão dos alunos sobre essas relações entre assuntos do livro didático e suas experiências, foi feita uma pergunta. A questão era saber se, caso os temas fossem trabalhados de forma relacionada à vida deles, poderiam fazer 
o jovem ser uma pessoa atuante e crítica na sociedade em que vive. Seguem respostas dadas pelos alunos:

Sim, porque a pessoa poderia ter mais conhecimento que outras e então ele poderia criticar ideias erradas de outras pessoas (Nikael, 15 anos).

[Sim] Porque deveria saber mais, estudar mais e desenvolver uma crítica sobre isso (Agda, 17 anos, $2^{\circ}$ ano).

A aluna Agda, ao analisar as obras aprovadas pelo PNLD 2012 em atividade realizada para a produção dos dados da pesquisa, aponta a necessidade de um complemento quanto ao tema cidadania, evidenciando elementos de uma consciência crítica que anseia por maior conhecimento quanto a um conteúdo que tem ressonância na sua vida e na da comunidade. Deve-se destacar que um dos critérios eliminatórios específicos para o componente curricular História exige que as obras estimulem algumas reflexões sobre a sociedade contemporânea; será desclassificada aquela que não desperte "os alunos para a historicidade das experiências sociais, trabalhando conceitos, habilidades e atitudes, com vistas à construção da cidadania" (BRASIL, 2011, p. 17).

Rodrigo afirma que "se os jovens soubessem da História do Brasil talvez eles entendessem melhor e criticariam a sociedade em que vivemos". Para Rodrigo, que na atividade proposta analisou um capítulo sobre a ditadura militar brasileira e o processo posterior de abertura, o livro didático de História contribui para que se conheça a História do país; para ele, se todo jovem tivesse esse conhecimento, certamente a sociedade seria melhor.

O texto do edital do PNLD 2012, que orientou a produção e a aprovação dos livros analisados pelos alunos, dentre suas considerações sobre o ensino da História escolar chama a atenção para o objetivo central do ensino e aprendizagem de História:

Valorizam-se, contudo, as especificidades da História escolar, que deve favorecer a que os estudantes analisem diferentes situações históricas em seus aspectos espaço-temporais e conceituais, promovendo diversos tipos de relações, pelas quais seja possível estabelecer diferenças e semelhanças entre os contextos; identificar rupturas e continuidades no movimento histórico e, principalmente, situar-se como sujeito da história, porque a compreende e nela intervém (BRASIL, 2012). 
Um dos critérios eliminatórios no componente curricular História, expresso tanto no Edital quanto no Guia PNLD 2012, exige observar se a obra "orienta os alunos a pensarem historicamente, a reconhecerem as diferentes experiências históricas das sociedades e, com base nesse entendimento, a compreenderem as situações reais da sua vida cotidiana e do seu tempo" (BRASIL, 2011, p. 16).

Portanto, a partir da análise realizada pelos jovens alunos, pode-se afirmar que, mesmo com a exigência estabelecida no PNLD, os temas e os problemas levantados nos livros didáticos de História para alunos do Ensino Médio das escolas brasileiras são insuficientes para evidenciar as relações entre o passado e o presente e, assim, segundo os jovens, pouco contribuem para a compreensão da realidade em que vivem. As mediações necessárias dependem, quase sempre, da intervenção dos professores, nem sempre especialistas na disciplina.

\section{Considerações finais}

Os resultados e análises apresentados neste texto indicam que o uso da etnografia na pesquisa possibilitou construir uma aproximação com a vida escolar nesta situação específica, de uma Escola do Campo, que permitiu afirmar que as aulas de História ainda pouco dialogam com o tempo e a história dos sujeitos, nesse caso específico com os jovens e suas experiências históricas, sociais e culturais. Foi possível constatar, nas palavras dos alunos, que a ausência dessas relações acaba diminuindo a possibilidade de conhecer e compreender o mundo que os cerca, em especial as relações que constituem a vida de sua comunidade. (CHAVES, 2015).

Nesse sentido a opção pelo trabalho etnográfico justificou-se pela busca e pelo encontro de respostas que não se dariam a partir apenas da análise de documentos ou por entrevistas. A imersão do pesquisador no cotidiano escolar mostrou o quão pouco se sabe sobre as dinâmicas de uso dos livros nas aulas de História, ou sobre a relação do conteúdo do livro didático com a realidade que constitui a vida escolar.

Nesta imersão de longo tempo nas aulas de História em uma Escola do Campo, foi possível verificar que o livro didático é um objeto constitutivo das dinâmicas de sala de aula e, sobretudo, fortemente ligado à vida do aluno. Os jovens, sujeitos do conhecimento histórico, buscam no livro o conhecimento mais sistematizado quando a explicação dos professores não foi suficiente, ou quando ocorre sua ausência em uma aula, situação em que apontam as dificuldades para dar sentido aos conteúdos. 
Os alunos colaboradores mostraram-se muitas vezes criativos em se tratando do uso deste artefato, apropriando-se e reelaborando os conteúdos do livro, provocando questões e explicações não apresentadas inicialmente pelos professores. Apesar dos limites da pesquisa, essa participação dos alunos na produção das aulas, em geral ausente nas investigações sobre o uso do livro didático, abre possibilidades de esclarecer os processos de produção do conhecimento histórico nas aulas, bem como o papel ativo que os alunos podem ter em tal processo.

Em outras palavras, deve-se dizer que somente o trabalho de campo intensivo e prolongado para observar e registrar os processos de uso dos livros permitiu a descrição analítica das dinâmicas das salas de aula em que as observações aconteceram. Abriu a possibilidade de o pesquisador se aproximar dos jovens alunos e dos professores para conhecer suas formas de compreender os livros, de trabalhar com eles, levantar seus pontos de vista sobre as coleções analisadas e, ainda, discutir significados dos conhecimentos construídos e sobre a aprendizagem histórica a partir do livro didático.

\section{REFERÊNCIAS}

ABUD, Katia Maria. O livro didático e a popularização do saber histórico. In: SILVA, Marcos A. (Org.). Repensando a história. Rio de Janeiro: Marco Zero, 1984. p. 81-87.

BATISTA, António Augusto Gomes. Um objeto variável e instável: textos, impressos e livros didáticos. In: ABREU, Márcia (Org.). Leitura, história e história da leitura. Campinas, SP: Mercado das Letras, 1999. p. 529-575.

BRASIL. Ministério da Educação e Cultura. Secretaria de Educação Fundamental. Parâmetros Curriculares Nacionais: História. Brasília: MEC/SEF, 1998.

BRASIL. Ministério da Educação. Secretaria de Educação Média e Tecnológica. Parâmetros Curriculares Nacionais: Ensino Médio. Brasília: MEC, 1999.

BRASIL, Ministério da Educação. Guia de livros didáticos - PNLD, 2012: História. Brasília: MEC, 2011.

BRASIL. Edital Ensino Médio consolidado. Edital de convocação para inscrição no processo de avaliação e seleção de obras didáticas para o Programa Nacional do Livro Didático PNLD 2012. DOU da União, 04 de dezembro de 2012, seção 3, página 60.

CHAVES, Edilson Aparecido. A música caipira em aulas de História: questões e possibilidades. 2006. Dissertação (Mestrado em Educação) - Programa de Pós-Graduação em Educação, NPPD/PPGE-UFPR. Curitiba, 2006. 
CHAVES, Edilson Aparecido. A presença do livro didático de história em aulas do Ensino Médio: estudo etnográfico em uma escola do campo. 2015. Tese (Doutorado em Educação) - Programa de Pós-Graduação em Educação, Universidade Federal do Paraná. Curitiba, 2015.

CHAVES, Edilson Aparecido; GARCIA, Tânia Maria F. Braga. Avaliação de livros de História por alunos do ensino médio. Revista Espaço Pedagógico, Passo Fundo, v. 21, n. 2, p. 336-357, jul./dez. 2014.

EDWARDS, Verónica. Os sujeitos no universo da escola: um estudo etnográfico no ensino primário. Tradução de Josely Vianna Baptista. São Paulo: Ática, 2003.

FONSECA, Selva Guimarães. Livros didáticos e paradidáticos de história. In: FONSECA, Selva Guimarães. Didática e prática de ensino de História. Campinas: Papirus, 2003.

FREITAG, Bárbara; MOTTA, Valéria Rodrigues; COSTA, Wanderly Ferreira. O estado da arte do Livro Didático no Brasil. Brasília: INEP, 1987.

GARCIA, Tânia M. F. Braga. Origens e questões da etnografia educacional no Brasil: um balanço de teses e dissertações (1981-1998). 2001. Tese (Doutorado em Educação) - FEUSP. São Paulo, 2001.

HOLLANDA, Guy. Um quarto de século de Programas e Compêndios de História para o ensino secundário brasileiro - 1931/1956. Rio de Janeiro: INEP/MEC, 1957.

MORAES, Marcelo Antonio Bueno. O papel do guia do livro didático de histórial PNLD no processo de escolha dos livros pelos professores dos anos finais do ensino fundamental. 2018. Dissertação (Mestrado em Educação) - Programa de Pós-Graduação em Educação, NPPD/PPGE-UFPR. Curitiba, 2018.

PELLEGRINI, Marco; DIAS, Adriana Machado; GRINBERG, Keila. Novo olhar: História. v. 2, 1. ed. São Paulo: FTD, 2010.

ROCKWELL, Elsie; EZPELETA, Justo. A escola: relato de um processo inacabado de construção. Currículo sem Fronteiras, v. 7, n. 2, p. 131-147, jul./dez. 2007.

SILVA, Anne Cacielle Ferreira da. Estado do conhecimento sobre o livro didático de história em dissertações e teses produzidas em programas de pós-graduação no Brasil (1990-2015). 2018. Tese (Doutorado em Educação) - Programa de Pós-Graduação em Educação, Universidade Federal do Paraná. Curitiba, 2018.

TIMBÓ, Isaíde Bandeira. Livro didático de história: cultura material escolar em destaque. In: SIMPÓSIO NACIONAL DE HISTÓRIA, 25., Fortaleza, 2009. Texto apresentado. ANPUH, 2009. p. 1-9.

Texto recebido em 29/07/2019.

Texto aprovado em 02/09/2019. 